\title{
SPECT vs. PET in cardiac innervation imaging: clash of the titans
}

\author{
Rudolf A. Werner ${ }^{1,2,3} \cdot$ Xinyu Chen ${ }^{2,3} \cdot$ Mitsuru Hirano $^{4}$ - Steven P. Rowe ${ }^{1} \cdot$ Constantin Lapa ${ }^{2} \cdot$ Mehrbod S. Javadi $^{1}$. \\ Takahiro Higuchi ${ }^{2,3,4}$ (B)
}

Received: 1 June 2018 / Accepted: 28 June 2018 / Published online: 3 July 2018

(c) The Author(s) 2018

\begin{abstract}
Purpose We aim to provide an overview of the conventional single photon emission computed tomography (SPECT) and emerging positron emission tomography (PET) catecholamine analogue tracers for assessing myocardial nerve integrity, in particular focusing on ${ }^{18} \mathrm{~F}$-labeled tracers.

Results Increasingly, the cardiac sympathetic nervous system (SNS) is being studied by non-invasive molecular imaging approaches. Forming the backbone of myocardial SNS imaging, the norepinephrine (NE) transporter at the sympathetic nerve terminal plays a crucial role for visualizing denervated myocardium: in particular, the single-photon-emitting NE analogue ${ }^{123}$ I-meta-Iodobenzylguanidine $\left({ }^{123} \mathrm{I}-\mathrm{mIBG}\right)$ has demonstrated favorable results in the identification of patients at a high risk for cardiac death. However, cardiac neuronal PET agents offer several advantages including improved spatio-temporal resolution and intrinsic quantifiability. Compared to their ${ }^{11} \mathrm{C}$-labeled counterparts with a short half-life (20.4 min), novel ${ }^{18}$ F-labeled PET imaging agents to assess myocardial nerve integrity have the potential to revolutionize the field of SNS molecular imaging. The longer half-life of ${ }^{18} \mathrm{~F}(109.8 \mathrm{~min})$ allows for more flexibility in the study design and delivery from central cyclotron facilities to smaller hospitals may lead to further cost reduction. A great deal of progress has been made by the first in-human studies of such ${ }^{18} \mathrm{~F}$-labeled SNS imaging agents. Moreover, dedicated animal platforms open avenues for further insights into the handling of radiolabeled catecholamine analogues at the sympathetic nerve terminal.

Conclusions ${ }^{18} \mathrm{~F}$-labeled imaging agents demonstrate key properties for mapping cardiac sympathetic nerve integrity and might outperform current SPECT-based or ${ }^{11} \mathrm{C}$-labeled tracers in the long run.
\end{abstract}

Keywords ${ }^{18} \mathrm{~F}$-LMI1195 $\cdot{ }^{11} \mathrm{C}$-hydroxyephedrine $\cdot{ }^{123}$ I-metaiodobenzylguanidine $\cdot$ Positron emission tomography $\cdot$ Single photon emission computed tomography $\cdot$ Sympathetic nerve

Takahiro Higuchi

thiguchi@me.com

1 Division of Nuclear Medicine and Molecular Imaging, The Russell H. Morgan Department of Radiology and Radiological Science, Johns Hopkins University School of Medicine, Baltimore, MD, USA

2 Department of Nuclear Medicine, University of Wuerzburg, Oberduerrbacher Strasse 6, 97080 Würzburg, Germany

3 Comprehensive Heart Failure Center, University of Wuerzburg, Würzburg, Germany

4 Department of Biomedical Imaging, National Cardiovascular and Cerebral Center, Suita, Japan

\section{Introduction}

Heart failure (HF) is primarily characterized by a vicious cycle: myocardial injury leads to reduced cardiac output, which triggers myocardial sympathetic nervous system (SNS) hyperactivity, which in turn leads to further cardiac damage and ultimately to a further reduction of systolic function $[1,2]$. On a subcellular level, alterations of the myocardial SNS are manifest as an elevated plasma concentration of NE, an impaired function of NE transporter (uptake-1 mechanism) as well as by a reduced plasma clearance of NE in the synaptic cleft [3,4]. This phenomenon of "cardiac NE spillover" causes severe damage to cardiac myocytes via cyclic AMP-mediated calcium overloads, which result in a decrease of synthetic activity and viability [5]. Apart from that, a continuous oversupply of NE at the sympathetic nerve terminal triggers remodeling of the left 
ventricle and the development of hypertensive left ventricular hypertrophy [6]. Not surprisingly, those insights into HF pathophysiology paved the way for a therapeutic approach via sympathetic inhibition: the CIBIS-II trial demonstrated a decreased cardiac mortality rate in HF patients undergoing treatment with adrenergic beta blockers [7]. Of note, an incremental cost effectiveness ratio compared to other conventional cardiovascular treatments was documented [8]. On the contrary, the investigators of the "Sustained-release moxonidine in patients with HF (MOXCON)" trial examined the beneficial role of generalized sympathetic inhibition in HF using the imidazoline receptor agonist moxonidine and an increase in death rate led to early termination of this promising approach in HF treatment [9]. Taken together, the delicate balance of risk and benefit of therapeutic interventions of cardiac sympathetic nerve blockade emphasizes the pivotal role of non-invasive imaging to assess the current status of the cardiac SNS. Moreover, such imaging concepts could potentially be applied to stratify one's individual risk for sudden cardiac death or to determine the appropriate time-point at which to initiate further treatment for progressive HF. However, in contradistinction to conventional imaging modalities, molecular imaging using either single photon emission computed tomography (SPECT) or positron-emission tomography (PET) offers the unique opportunity to characterize alterations on a subcellular level and to gain deeper insights into cardiac disease development and early onset of HF [10]: Physiologic NE is stored in presynaptic vesicles and once a firing impulse has arrived at the nerve terminal, NE is exocitotically released into the synaptic cleft, where it is readily available for interacting with postsynaptic adrenoreceptors. After completing its primary task at the post-synapse, NE undergoes a recycling mechanism via the presynaptic NE transporter (uptake-1) and is stored in vesicles for potential re-use [10-12]. Comparable to its physiologic counterpart, radiolabeled NE analogues are taken up into the nerve terminals using the identical uptake-1 pathway and, therefore, impaired cardiac NE function is reflected by either decreased radiotracer uptake or increased tracer washout. Figure 1 summarizes commonly used catecholamine analogue tracers to assess cardiac sympathetic nerve integrity. In this review, we will discuss these radiolabeled SPECT and PET imaging agents for mapping the cardiac SNS, in particular focusing on recently introduced ${ }^{18} \mathrm{~F}$-labeled PET imaging probes.

\section{Myocardial SNS imaging using SPECT}

\section{${ }^{123}$ I-meta-iodobenzylguanidine ( ${ }^{123}$ I-mIBG) for risk stratification of HF-related events}

As a conventional scintigraphic approach, ${ }^{123} \mathrm{I}$-mIBG is a United States Food and Drug Administration-approved agent
Fig. 1 Chemical structures of radiolabeled catecholamine analogue tracers in comparison to physiological norepinephrine.

${ }^{123}$ I-meta-Iodobenzylguanidine $\left({ }^{123} \mathrm{I}\right.$-mIBG), ${ }^{11} \mathrm{C}$-hydroxyephedrine $\left({ }^{11} \mathrm{C}-\mathrm{HED}\right)$, $\mathrm{N}$-[3-Bromo-4- $\left(3-\left[{ }^{18}\right.\right.$ F] fluoropropoxy)-benzyl]-guanidine $\left({ }^{18}\right.$ F-LMI1195), ${ }^{18}$ F-fluoro3-hydroxyphenethylguanidine $\left({ }^{18} \mathrm{~F}-4 \mathrm{~F}-\mathrm{MPHG}\right)$<smiles>NC[C@@H](O)c1ccc(O)c(O)c1</smiles>

Norepinephrine<smiles>CN[C@@H](C)[C@H](O)c1cccc(O)c1</smiles><smiles>N=C(N)NCCc1ccc(F)c(O)c1</smiles>

${ }^{18} \mathrm{~F}-4 \mathrm{~F}-\mathrm{MHPG}$<smiles>N=C(N)NCc1cccc(Br)c1</smiles>

123|-mIBG<smiles>N=C(N)NCc1ccc(OCCC[18F])c(Br)c1</smiles>

${ }^{18}$ F-LMI1195<smiles>CNC[C@H](O)c1ccc(O)c(O)c1</smiles>

${ }^{11} \mathrm{C}$-Epinephrine 
that has found widespread use in Japan, the United States, and Europe $[13,14]$. Its prognostic role can be derived by calculating a heart-to-mediastinum ratio (HMR) obtained from planar scans, which can be considered as a semi-quantitative method to determine myocardial catecholamine uptake: patients below a certain HMR threshold are at a higher risk to experience cardiac events [15]. In a metaanalysis, Verberne et al. included 18 studies with a total of 1755 patients and concluded that decreased late HMR or increased myocardial ${ }^{123} \mathrm{I}-\mathrm{mIBG}$ washout are associated with a worse outcome compared to those patients without alterations in semi-quantitatively derived ${ }^{123} \mathrm{I}$-mIBG parameters [16]. These findings were further confirmed by the prospective "AdreView Myocardial Imaging for Risk Evaluation in Heart Failure (ADMIRE-HF)" trial, which emphasized the potential benefit of ${ }^{123} \mathrm{I}-\mathrm{mIBG}$ imaging for risk stratification in patients suffering from severe HF. A highly significant association between time of HF-related events and the HMR was derived, independent of other common clinical parameters, such as left ventricular ejection fraction (LVEF) or renal function [17]. In a similar vein, Nakajima et al. created dedicated mortality risk charts with ${ }^{123}$ I-mIBG imaging and clinical parameters (New York Heart Association Class (NYHA), Age, LVEF) with 2- and 5-year mortality risk estimations that aimed to provide a more flexible platform for short- and long-term therapeutic decision-making in patients suffering from congestive HF [18].

\section{${ }^{123}$ I-mIBG as a risk stratification tool for potential device therapy candidates}

Apart from risk stratification for HF-related cardiac events, the amount of denervated myocardium as assessed by ${ }^{123} \mathrm{I}$-mIBG is being increasingly utilized to guide the referring treating cardiologist in regards to what time to initiate further treatment, in particular by implantation of cardioverter defibrillators (ICD). ICD shocks for ventricular tachyarrhythmias are of utmost importance for secondary prevention of sudden cardiac death. Although the documented shock frequency varies among different studies [19], a considerable proportion of patients receive an inappropriate shock, in particular with single-chamber devices [20]. Apart from this risk of malfunction, up to $65 \%$ never have an appropriate ICD discharge after ICD implantation [21]. A recent published post hoc analysis performed by Verschure et al. demonstrated that the combination of late HMR and LVEF was associated with freedom of appropriate ICD therapy: consequently, it was concluded that ${ }^{123}$ I-mIBG scintigraphy might be helpful in excluding those patients who might not benefit from ICD implantation [22]. A combination of ${ }^{123} \mathrm{I}-\mathrm{mIBG}$ and the "Seattle Heart Failure Model" using demographic as well as clinical markers improved risk stratification in high-risk HF patients for potential therapeutic assessment with ICD or cardiac resynchronization therapy (CRT) [23]. The latter therapeutic approach has proven to be highly effective in patients with complete left bundle branch block, but an extensive body of literature demonstrated that a significant number of patients receiving CRT have to deal with device complications [24]. Thus, analogous to ICD therapy, ${ }^{123} \mathrm{I}-\mathrm{mIBG}$ imaging might meet this urgent clinical need of selecting appropriate candidates for CRT initiation. Utilizing a baseline ${ }^{123}$ I-mIBG scan, Nishioka et al. demonstrated that lower HMR could identify CRT non-responders [25]. The currently recruiting, event-driven Phase IIIb multicenter, randomized, prospective "International Study to Determine if AdreView Heart Function Scan Can be Used to Identify Patients With Mild or Moderate Heart Failure (HF) That Benefit From Implanted Medical Device (ADMIRE-ICD)" trial may provide further insights into the efficacy of ${ }^{123} \mathrm{I}$-mIBG for selecting patients who most likely benefit from ICD implantation [26]. Taken together, these data suggest that ${ }^{123} \mathrm{I}$-mIBG can be used to guide the treating cardiologist to identify high-risk patients who benefit from device therapy. Thus, one might speculate that the non-invasive assessment of myocardial nerve integrity using ${ }^{123}$ I-mIBG has the potential to outperform current selection criteria, such as LVEF or electrocardiogramderived QRS duration [13, 27].

\section{${ }^{123}$ I-mIBG for other clinical scenarios}

Scintigraphic assessment of the SNS of the heart might be also helpful in heart-transplant recipients, as sympathetic reinnervation could successfully be monitored by ${ }^{123} \mathrm{I}$-mIBG up to 1 year after operation [28]. Thus, ${ }^{123}$ I-mIBG could have utility in selecting appropriate transplantation candidates or might contribute to further determining expected post-surgical survival rates [13]. Gerson et al. studied 343 diabetic and 618 nondiabetic subjects with NYHA class II or III HF and the combination of diabetes mellitus and HMR predicted HF progression independently. Thus, diabetic patients with impaired SNS function of the heart seem to be at higher risk and consequently, lifestyle changes could be further promoted or anti-diabetic treatment could be intensified among those individuals [29]. Apart from that, Sobajima et al. demonstrated immediate improvement of SNS activity (assessed by ${ }^{123}$ I-mIBG washout rate) after transcatheter aortic valve implantation (TAVI) in patients suffering from aortic valve stenosis. Hence, ${ }^{123}$ I-mIBG might serve as a risk stratification tool or could also monitor the therapeutic efficacy of TAVI [30]. Moreover, ${ }^{123}$ I-mIBG imaging has also been used to evaluate cardiac involvement in multiorgan diseases: On a small cohort of 5 patients, Yamamoto et al. demonstrated that cardiac sympathetic nerve activity is reduced in subjects diagnosed with Anderson-Fabry Disease (AFD) [31]. These preliminary findings were further corroborated on a 
larger scale in 25 patients with genetically proven AFD: in a comparison of ${ }^{123} \mathrm{I}-\mathrm{mIBG}$ and cardiac magnetic resonance imaging, impaired sympathetic nerve function preceded myocardial structural damage, such as fibrosis [32]. Apart from that, ${ }^{123} \mathrm{I}-\mathrm{mIBG}$ is also considered as a valuable risk stratification tool in non-cardiac diseases, such as neurogenerative disorders: it has been proven that HMR based on ${ }^{123}$ I-mIBG scintigraphy can differentiate between Dementia with Lewy Bodies and Alzheimer disease even in patients without parkinsonism [33].

\section{PET imaging agents for myocardial SNS assessment- $-{ }^{11} \mathrm{C}$-labeled tracers}

Despite its potential incremental value over conventional clinical parameters, ${ }^{123} \mathrm{I}$-mIBG suffers from several drawbacks. HMR is a global marker of cardiac nerve integrity, and thus it does not provide any further details of regional heterogeneity of denervated myocardium in viable border zones [10, 34]. However, cardiac neuronal PET imaging agents offer several advantages over ${ }^{123} \mathrm{I}$-mIBG SPECT including improved spatio-temporal resolution and quantification approaches [35]. Hence, in contradistinction to a global assessment of the cardiac nerve integrity using ${ }^{123}$ I-mIBG-derived HMR, PET-based assessment of denervated myocardium opens avenues for regional analysis of different myocardial areas simultaneously (e.g., infarct zone, border zone or remote myocardium) [10].

Several ${ }^{11} \mathrm{C}$-labeled catecholamine analogue radiotracers have been investigated to assess myocardial SNS: The three most commonly used radiotracers are ${ }^{11} \mathrm{C}$-hydroxyephedrine $\left({ }^{11} \mathrm{C}\right.$-HED), ${ }^{11} \mathrm{C}$-epinephrine and ${ }^{11} \mathrm{C}$-phenylepinephrine [12, 35]. All of these carbon-11 compounds differ in their kinetic properties, such as their affinity for neuronal uptake- 1 as well as susceptibility to degrading enzymes, e.g. monoamine oxidase (MAO) and catechol- $O$-methyltransferase [36]. Hence, a combination of multiple PET radiotracers with such distinct differences in their properties may offer more profound insight into cardiac sympathetic neurotransmission in the failing heart $[10,35]$ : in an ${ }^{11} \mathrm{C}$-labeled tripleradiotracer approach in otherwise healthy heart-transplant recipients, different underlying characteristics in catecholamine handling after cardiac transplantation was demonstrated [37].

In clinical trials and daily clinical routine, ${ }^{11} \mathrm{C}$-HED is the most widely used PET radiotracer to assess sympathetic nerve conditions: in a recent study, a low global ${ }^{11} \mathrm{C}$-HED retention was linked to poorer overall survival in patients with LV dysfunction [38]. Analogous to its scintigraphybased counterpart (ADMIRE-HF) [17], the prospective "Prediction of ARrhythmic Events with Positron Emission Tomography (PAREPET)" trial proved that the volume of denervated myocardium is a strong predictor of sudden cardiac arrest, independent of other clinical parameters, such as LVEF, infarct volume or hybernating myocardium. Quantitatively, each $1 \%$ increase in the denervated myocardial volume was associated with a $5.7 \%$ increase in sudden cardiac arrest. Hence, this PET-driven imaging assessment of myocardial sympathetic denervation could also be helpful in differentiating between low- and high-risk patients who most likely benefit from ICD implantation [39]. As a common comorbidity in chronic heart disease [40], Hall et al. investigated the beneficial use of ${ }^{11} \mathrm{C}$-HED in HF patients suffering from obstructive sleep apnea (OSA) under continuous positive airway pressure (cPAP) therapy. Of note, short-term cPAP therapy of 6-8 weeks increased ${ }^{11} \mathrm{C}-\mathrm{HED}$ retention and, therefore, indicated an improved myocardial SNS. This might pave the way to link potential alterations in ${ }^{11} \mathrm{C}$-HED retention indices to clinical outcome in patients suffering from OSA [41].

\section{Novel cardiac neuronal PET imaging agents: ${ }^{18} \mathrm{~F}$-labeled radiotracers}

${ }^{11} \mathrm{C}$-labeled radiotracers are currently the most frequently used cardiac PET imaging agents for mapping sympathetic nerve conditions of the heart. However, higher expenses for purchase, maintenance of costly on-site cyclotrons, and the necessity of staff to prepare such radiopharmaceuticals increases the financial burden for both patients as well as for primary or secondary care hospitals. The financial burden for radiotracer production is a consideration for practitioners as to what extent ${ }^{11} \mathrm{C}$-HED should be employed in daily clinical routine [26]. On the other hand, ${ }^{18} \mathrm{~F}$-labeled radiotracers have a significantly longer half-life (110 $\mathrm{min})$ and might overcome these hurdles. First, the longer halflife allows for delivery from central cyclotron facilities to smaller hospitals with stand-alone PETs, which has proven to be cost-effective for the commonly used oncology imaging agent 2-deoxy-2- ${ }^{18}$ F-fluoro-D-glucose [42]. Such ${ }^{18} \mathrm{~F}$-labeled cardiac neuronal imaging agents could even be distributed by commercial vendors [43]. Second, the longer half-life would also allow for flexibility in the study protocol, e.g. by facilitating the acquisition of both early and delayed time point imaging analogous to ${ }^{123} \mathrm{I}-\mathrm{mIBG}$. Moreover, fluoride introduction into PET agents increases the stability of a radiopharmaceutical, as the risk of metabolism at sensitive positions is reduced [44]. Consequently, ${ }^{18} \mathrm{~F}$-labeled radiotracers can help realize the full potential of PET imaging technology and, therefore, novel cardiac SNS imaging agents have recently been introduced, including ${ }^{18}$ F-LMI1195 as well as ${ }^{18}$ F-Fluoro-Hydroxyphenethylguanidines $\left[{ }^{18} \mathrm{~F}\right.$-fluoro-3-hydroxyphenethylguanidine $\left({ }^{18} \mathrm{~F}-4 \mathrm{~F}-\mathrm{MPHG}\right)$ and its structural isomer 
$3-{ }^{18}$ F-fluoro-4-hydroxyphenethylguanidine $\left.\left({ }^{18} \mathrm{~F}-3 \mathrm{~F}-\mathrm{PHPG}\right)\right]$ [44].

\section{Fluorobenzylguanidine $\left({ }^{18} \mathrm{~F}-\mathrm{LM} 11195\right)$}

Sharing a benzylguanidine structure similar to its SPECT counterpart ${ }^{123} \mathrm{I}$-mIBG, ${ }^{18} \mathrm{~F}$-LMI1 195 is not subject to further metabolism by enzymes such as MAO. As a major advantage, it can be easily obtained by a simple one-step

${ }^{18} \mathrm{~F}$ replacement reaction [44].

Using a cell membrane-binding assay, it was demonstrated that ${ }^{18} \mathrm{~F}$-LMI1195 is taken up via uptake- 1 mechanism into the presynaptic nerve terminal. Moreover, in an in vitro blocking study using the potent uptake-1 blocking agent desipramine (DMI), the high specificity of ${ }^{18} \mathrm{~F}$ LMI1195 to uptake-1 was further corroborated [45]. Utilizing isolated perfused rabbit hearts to avoid systemic recirculation and metabolism of the radiotracer, a flowdependent decrease of the first-pass radiotracer extraction fraction was demonstrated: therefore, one might speculate that the initial uptake depends on the radiotracer quantity in the extracellular spaces which is limited by blood flow [46]. However, Yu et al. examined a denervated rabbit model and after an initial uptake in the first $2 \mathrm{~min}$ in both innervated and denervated areas, ${ }^{18} \mathrm{~F}$-LMI1 195 was rapidly washed out thereafter [47].

After being taken up into presynaptic nerve terminals via uptake-1, it was questioned whether ${ }^{18} \mathrm{~F}$-LMI1195 is stored in presynaptic vesicles [10]. Therefore, in an in vivo headto-head comparison using healthy rabbits, the most commonly used SPECT/PET catecholamine analogue radiotracers $\left({ }^{123} \mathrm{I}\right.$-mIBG, ${ }^{11} \mathrm{C}$-HED $)$ and ${ }^{18} \mathrm{~F}$-LMI1195 were studied by our research group: all of these tracers could be blocked by pretreatment with the potent uptake- 1 blocker DMI before tracer injection. Similar findings of a selective NET inhibitor blockage via DMI has been previously reported for both ${ }^{123}$ I-mIBG and ${ }^{18} \mathrm{~F}$-LMI1195 in the rabbit heart [45]. However, distinct radiotracer properties were revealed using a DMI chase protocol (i.e., DMI administered after tracer delivery): retention kinetics of the benzylguanidinebased tracers ${ }^{123}$ I-mIBG and ${ }^{18} \mathrm{~F}$-LMI1195 remained stable, while ${ }^{11} \mathrm{C}$-HED washout increased significantly. Integrating these data, it can be hypothesized that ${ }^{123} \mathrm{I}-\mathrm{mIBG}$ and ${ }^{18} \mathrm{~F}$ LMI1195 are stably stored in presynaptic vesicles (resistant to NET inhibitor chase) and, therefore, mimic physiological NE turnover. On the contrary, ${ }^{11} \mathrm{C}$-HED undergoes a continuous cycle of NET uptake and release at the nerve terminal (Fig. 2) [35]. These findings were further corroborated by electric field stimulation in isolated perfused rabbit hearts: this approach lead to increased washout rate of ${ }^{18} \mathrm{~F}$-LMI1 195, as it provoques vesicular NE release [46]. Of note, all of those studies were conducted using rabbit myocardium: similar to the human heart, the contribution of $\mathrm{NE}$ clearance to neuronal uptake- 1 is also pronounced in rabbits and, therefore, the rabbit heart serves as a suitable platform to mimic human cardiac nerve status $[48,49]$. However, our research group also recently investigated (vesicle-poor) SK$\mathrm{N}$-SH cells vs. (vesicle-rich) $\mathrm{PC} 12$ cells in combination with ${ }^{18} \mathrm{~F}$-LMI1 195 and we found that stimulants for storage vesicle turnover (reserpine, high potassium chloride) enhanced ${ }^{18} \mathrm{~F}$-LMI1195 washout from PC12 cells, while radiotracer retention remained stable in SK-N-SH cells [50].

Multiple studies have reported on the high specificity of ${ }^{18} \mathrm{~F}$-LMI1195 for uptake-1 in different species, such as monkeys. A clear delineation of the myocardium was visualized with a significantly higher heart-to-background ratio, mainly due to a rapid washout from the lung and liver as well as a quick radiotracer clearance from the blood. Compared to ${ }^{123} \mathrm{I}$-mIBG, a three-fold higher heart-to-liver ratio could be derived for ${ }^{18} \mathrm{~F}$-LMI1195 in cynomonkeys [45]. However, species- and radiotracer-dependent variations among different cardiac catecholamine analogue tracers have to be taken into account. For example in Wistar rats, cardiac uptake of ${ }^{18} \mathrm{~F}$-LMI1195 was significantly altered using the NE uptake-2 inhibitor phenoxybenzamine (but not by the uptake-1 blocker DMI). Thus, in contradistinction to other species, ${ }^{18} \mathrm{~F}$-LMI1195 is primarily a substrate of uptake-2 in rats [51]. However, ${ }^{11} \mathrm{C}$-HED can be successfully inhibited by the uptake-1 blocker DMI in rat hearts and, therefore, ${ }^{11} \mathrm{C}$-HED uptake has a high affinity to neuronal uptake-1 in that species. Of note, this does not apply to ${ }^{123} \mathrm{I}$-mIBG: analogous to ${ }^{18} \mathrm{~F}$-LMI1195, ${ }^{123} \mathrm{I} /{ }^{131} \mathrm{I}$-mIBG demonstrated distinct characteristics of uptake mechanism that are compatible with a significant contribution from nonneuronal uptake-2 in the rat heart [52]. The underlying chemical structure (benzylguanidine) might explain the similarities between mIBG and LMI1195 in the rat myocardium. Hence, to investigate catecholamine analogue radiotracer handling in the nerve terminal, the animal platform to test a particular SNS imaging agent has to be chosen with extreme caution [52]. ${ }^{18} \mathrm{~F}-\mathrm{LMI} 1195$ might also allow for detection and quantification of loco-regional areas of denervation. In denervated rabbit myocardium, ${ }^{18} \mathrm{~F}$-LMI1195 could differentiate between innervated vs. denervated areas, while the reference myocardial perfusion PET radiotracer ${ }^{18} \mathrm{~F}$-flurpiridaz demonstrated no abnormalities. Of note, ${ }^{18} \mathrm{~F}$-LMI1195 was able to monitor reinnervation in previous denervated areas ( $2 \mathrm{vs}$. 12 weeks post-denervation) [47].

Noteworthy, ${ }^{18}$ F-LMI1 195 is the only ${ }^{18}$ F-labeled catecholamine analogue radiotracer that has entered phase-1 and phase- 2 trials. Sinusas et al. reported on promising radiotracer characteristics with favorable biodistribution: over $5 \mathrm{~h}$, stable myocardial activity, which was uniform throughout the myocardium, as well as rapid blood clearance was demonstrated. Dynamic PET revealed excellent heart-to-lung and heart-to-liver ratios (Fig. 3). In the twelve 
Fig. 2 a Averaged time activity curves and $\mathbf{b}$ representative short-axis images of in vivo rabbit cardiac PET imaging. Desipramine (DMI) chase (i.e., DMI administered after tracer delivery) enhanced ${ }^{11} \mathrm{C}$-Hydroxyephedrine $\left({ }^{11} \mathrm{C}\right.$-HED) tracer washout, while ${ }^{18} \mathrm{~F}$-LMI1195 washout remained stable. c Results of in vivo rabbit ${ }^{123}$ I-metaiodobenzylguanidine ( $\left.{ }^{123} \mathrm{I}-\mathrm{mIBG}\right)$ planar scintigraphy of the chest. Similar to ${ }^{18} \mathrm{~F}$ LMI1195, DMI chase did not change cardiac distribution of

${ }^{123}$ I-mIBG. This might be due to the underlying benzylguanidine structure shared by both radiotracers. Dotted lines indicate regions of interest in both heart and mediastinum. Modified from Werner et al. [35] () by the Society of Nuclear Medicine and Molecular Imaging, Inc.
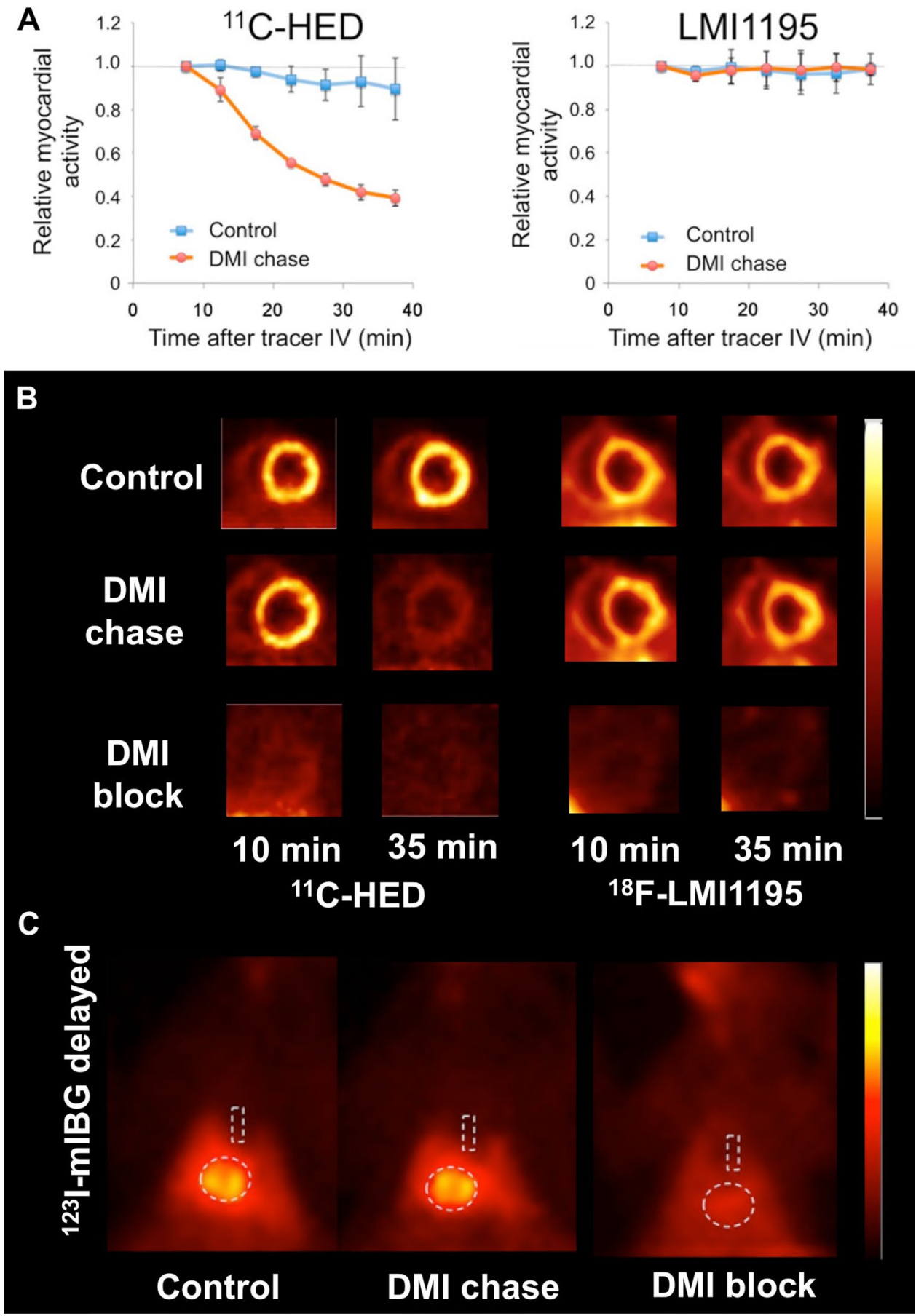

healthy volunteers, no adverse events or safety concerns were documented. Dosimetrically, the most critical organ was identified as the urinary bladder wall, followed by the kidneys. However, the mean effective dose was rather low and comparable to ${ }^{123} \mathrm{I}-\mathrm{mIBG}$ [53]. Of note, in a recently published head-to-head comparison of ${ }^{18}$ F-LMI1195 and ${ }^{11} \mathrm{C}-\mathrm{HED}$, preliminary assessment in 9 participants revealed comparable estimates of cardiac autonomic nervous function. However, compared to its ${ }^{11} \mathrm{C}$-based counterpart, the ${ }^{18} \mathrm{~F}$-labeled imaging agent demonstrated superior kinetics, in particular for early cardiac imaging [54]. Hence, this phase-2 trial might pave the way for a phase- 3 trial, which would further investigate the potential benefit of ${ }^{18} \mathrm{~F}$-LMI1195 for risk stratification among HF patients.

\section{${ }^{18}$ F-fluoro-hydroxyphenethylguanidines}

Apart from ${ }^{18}$ F-LMI1 195, two other ${ }^{18}$ F-labeled catecholamine analogue radiotracers have been introduced, namely ${ }^{18}$ F-4F-MPHG and ${ }^{18}$ F-3F-PHPG. Both radiotracers were 


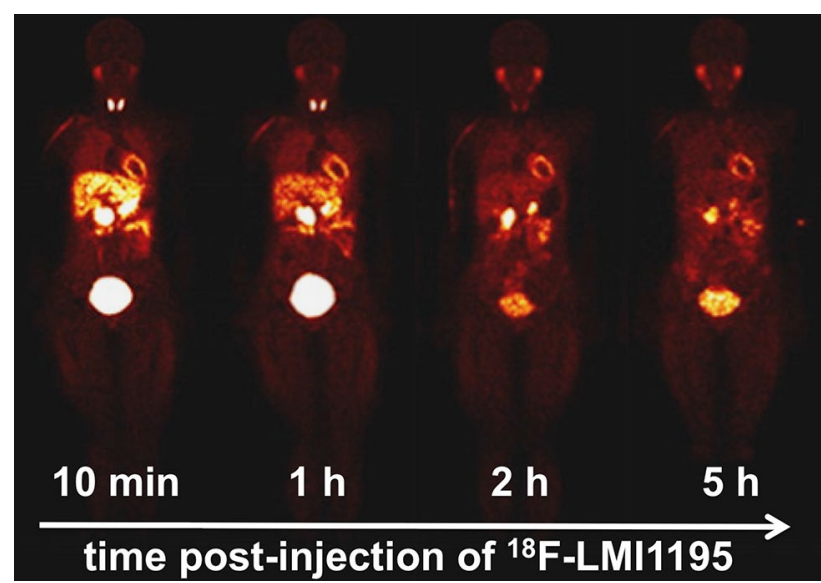

Fig. 3 Representative sequences of whole-body ${ }^{18}$ F-LMI1195 images in healthy volunteers approximately $10 \mathrm{~min}, 1,2$ and $5 \mathrm{~h}$ post-injection. Modified from Sinusas et al. [53] (C) by the Society of Nuclear Medicine and Molecular Imaging, Inc.

taken up more slowly and demonstrated significantly longer neuronal retention times compared to ${ }^{11} \mathrm{C}-\mathrm{HED}$ or ${ }^{11} \mathrm{C}-\mathrm{mIBG}$ in isolated rat hearts, mainly due to efficient storage inside NE storage vesicles [55]. Such key characteristics might be of utmost importance in kinetic analyses of regional nerve density assessment, as such radiotracers are capable of reflecting even modest alterations of cardiac sympathetic nerve conditions without being hampered by the blood flow effect. Common sympathetic nerve agents such as ${ }^{11} \mathrm{C}$-HED or ${ }^{123} \mathrm{I}-\mathrm{mIBG}$ are too rapidly taken up via uptake- 1 to allow for reliable compartmental modeling of their kinetics. Thus, the neuronal uptake for ${ }^{11} \mathrm{C}$-HED by uptake- 1 from extracellular space $(\mathrm{k} 3)$ is much faster than $\mathrm{k} 2$ (clearance from extracellular space back to plasma), i.e., $\mathrm{k} 3 \gg \mathrm{k} 2$. Consequently, ${ }^{11} \mathrm{C}$-HED retention measurements are not sensitive to moderate loss in nerve integrity and rather limited to myocardial regions in which nerve losses are severe [43]. However, the phenethylguanidine-like structure of ${ }^{18} \mathrm{~F}-4 \mathrm{~F}-$ MPHG and ${ }^{18} \mathrm{~F}-3 \mathrm{~F}-\mathrm{PHPG}$ overcomes these hurdles as they offer the main advantage of slow neuronal uptake and long neuronal retention [55].

In-vivo imaging studies in monkeys further corroborated the favorable kinetic properties of both ${ }^{18} \mathrm{~F}$-labeled radiotracers, as the myocardium could be clearly delineated. In an in vivo blocking study with varying amounts of DMI, retention indices of ${ }^{18} \mathrm{~F}-4 \mathrm{~F}-\mathrm{MPHG}$ decreased with increasing levels of the uptake-1 blocking agent. The obtained "net uptake rate" constant, derived from compartmental modeling or Patlak analysis of ${ }^{18} \mathrm{~F}-4 \mathrm{~F}-\mathrm{MPHG}$ kinetics, also declined dose-dependently with increasing DMI doses [56]. Thus, these compounds seem to have optimal kinetics and can allow for quantitative assessment of even a slight loss of cardiac sympathetic nerve density or regional denervation [44].
${ }^{18} \mathrm{~F}-4 \mathrm{~F}-\mathrm{MPHG}$ and ${ }^{18} \mathrm{~F}-3 \mathrm{~F}-\mathrm{PHPG}$ have been tested in humans and both imaging agents demonstrated clear delineation of the myocardium along with low liver and lung uptake. Kinetic analyses of both radiotracers using Patlak demonstrated encouraging results and regional mapping of cardiac nerve integrity in humans seems feasible [57].

Table 1 summarizes the herein presented SPECT and PET catecholamine analogue tracers to assess cardiac sympathetic nerve conditions, along with several advantages and limitations of each agent.

\section{Conclusions}

In this review, we provided an overview of the most commonly used SPECT and PET catecholamine analogue radiotracers for mapping myocardial nerve integrity. ${ }^{123} \mathrm{I}-\mathrm{mIBG}$ is considered to be the "Work Horse" in daily clinical routine [13] and multiple studies have demonstrated its benefit in different clinical scenarios. The prospective ADMIREHF trial showed its prognostic capability in identifying HF patients at risk, independent of other clinical parameters such as LVEF [17]. Moreover, the currently event-driven recruiting ADMIRE-ICD trial will determine the role of this imaging approach in selecting appropriate candidates for left-ventricular assistant device therapy [26]. However, ${ }^{123} \mathrm{I}$-mIBG merely provides a global assessment of cardiac nerve integrity, but novel innovative techniques such as Cadmium-zinc-telluride scanners may provide further information beyond available standard planar imaging techniques [58]. In contradistinction to SPECT, neuronal PET imaging agents offer several advantages, such as improved spatio-temporal resolution or regional analysis of different myocardial areas [10]. Multiple ${ }^{11} \mathrm{C}$-labeled catecholamine analogue PET radiotracers have been investigated to assess myocardial SNS: in particular, the prospective PAREPET trial demonstrated a strong association between the volume of denervated myocardium assessed by ${ }^{11} \mathrm{C}-\mathrm{HED}$ and cardiac events [39]. Compared to their ${ }^{11} \mathrm{C}$-labeled counterparts, the longer half-life of ${ }^{18} \mathrm{~F}$ allows for delivery from central cyclotron facilities to smaller hospitals with stand-alone PET scanners and, consequently, such ${ }^{18} \mathrm{~F}$-labeled cardiac imaging agents could even be distributed by commercial vendors. Thus, a costly on-site cyclotron is not needed and the financial burden for the healthcare system may be significantly reduced. Moreover, ${ }^{18} \mathrm{~F}$-labeled radiotracers also allow for more flexibility in the study protocol, such as delayed imaging [44]. The ${ }^{18} \mathrm{~F}$-labeled imaging agents included in this review $\left({ }^{18} \mathrm{~F}\right.$-LMI1195, ${ }^{18} \mathrm{~F}-4 \mathrm{~F}-\mathrm{MPHG}$ and $\left.{ }^{18} \mathrm{~F}-3 \mathrm{~F}-\mathrm{PHPG}\right)$ demonstrate excellent imaging quality and key properties such as reduced background uptake due to favorable heart-to-liver ratios, regional assessment of different myocardial areas, and/or kinetic behavior at the nerve 
Table 1 Head-to-head comparison of single-photon emission computed tomography (SPECT) vs. positron emission tomography (PET) agents for cardiac innervation imaging, along with several advantages and limitations

\begin{tabular}{|c|c|c|c|}
\hline Imaging Modality & Catecholamine analogue tracer & Advantages & Limitations \\
\hline SPECT & ${ }^{123} \mathrm{I}-\mathrm{mIBG}$ & $\begin{array}{l}\text { Long-standing experience }[13] \\
\text { Food-and-drug administration approved } \\
{[11]} \\
\text { Considered as the "work horse" }[13,26] \\
\text { Clincially well-established HMR ratio } \\
\text { [15] } \\
\text { Evidence from different prospective } \\
\text { trials (ADMIRE-HF, ADMIRE-ICD) } \\
\text { [17] }\end{array}$ & $\begin{array}{l}\text { HMR as a global marker of cardiac nerve } \\
\text { integrity [10] } \\
\text { No regional analysis of different myocar- } \\
\text { dial areas }[10,44] \\
\text { HMR primarily obtained by planar } \\
\text { images [15] } \\
\text { Cost-effectiveness data are lacking [13] }\end{array}$ \\
\hline \multirow[t]{3}{*}{ PET } & ${ }^{11} \mathrm{C}$-Hydroxyephedrine & $\begin{array}{l}\text { Higher spatio-temporal resolution [11] } \\
\text { Most widely used cardiac sympathetic } \\
\text { nerve PET radiotracer [11] } \\
\text { Denervated myocardium as a strong } \\
\text { predictor of sudden cardiac arrest } \\
\text { (PAREPET trial) [39] } \\
\text { Quantitative assessment of different } \\
\text { myocardial areas [44] }\end{array}$ & $\begin{array}{l}\text { High financial burden [44] } \\
\text { Short half-life of }{ }^{11} \mathrm{C}(20.4 \text { min) limits the } \\
\text { design of novel imaging agents [44] } \\
\text { Potential cold-mass effect of }{ }^{11} \mathrm{C}[59] \\
\text { Phase-2 study: superior kinetics of }{ }^{18} \mathrm{~F}- \\
\text { LMI1195 compared to }{ }^{11} \mathrm{C}-\mathrm{HED}[54]\end{array}$ \\
\hline & ${ }^{18}$ F-LMI1195 & $\begin{array}{l}\text { Simple one-step }{ }^{18} \mathrm{~F} \text { replacement reac- } \\
\text { tion [44] } \\
\text { First }{ }^{18} \mathrm{~F} \text {-labeled radiotracer in a phase-1 } \\
\text { and }-2 \text { trial }[53,54] \\
\text { Longer half-life }(110 \text { min): flexibility in } \\
\text { the study protocol, higher flexibility in } \\
\text { producing novel SNS cardiac imaging } \\
\text { agents [11, 44] } \\
\text { Readily transported and stored into } \\
\text { synaptic vesicles [35] } \\
\text { Phase } 2 \text { study: superior kinetics of }{ }^{18} \mathrm{~F}- \\
\text { LMI1195 [54] }\end{array}$ & $\begin{array}{l}\text { Limited to university hospitals/tertiary } \\
\text { referral hospitals } \\
\text { No data available regarding potential } \\
\text { benefit in risk stratification among HF } \\
\text { patients }\end{array}$ \\
\hline & $\begin{array}{l}{ }^{18} \text { F-Fluoro-Hydroxyphenethyl-guan- } \\
\text { idines }\left({ }^{18} \mathrm{~F}-4 \mathrm{~F}-\mathrm{MPHG} \text { and }{ }^{18} \mathrm{~F}-3 \mathrm{~F}-\right. \\
\text { PHPG) }\end{array}$ & $\begin{array}{l}\text { Slow uptake and longer neuronal reten- } \\
\text { tion times: potential to reflect even } \\
\text { modest alterations of cardiac sympa- } \\
\text { thetic nerve conditions [55] } \\
\text { Feasibility of compartmental modeling } \\
\text { or Patlak analysis [55, 57] } \\
\text { First-in-human study: low liver and lung } \\
\text { uptake [57] }\end{array}$ & $\begin{array}{l}\text { Limited to university hospitals/tertiary } \\
\text { referral hospitals } \\
\text { No data available regarding potential } \\
\text { benefit in risk stratification among HF } \\
\text { patients }\end{array}$ \\
\hline
\end{tabular}

AdreView myocardial imaging for risk evaluation in heart failure (ADMIRE-HF), International Study to determine if AdreView heart function scan can be used to identify patients with mild or moderate heart failure (HF) that benefit from implanted medical device (ADMIRE-ICD), heart-to-mediastinum ratio (HMR), Prediction of ARrhythmic events with positron emission tomography (PAREPET)

${ }^{123} \mathrm{I}$-mIBG ${ }^{123}$ I-meta-Iodobenzylguanidine, ${ }^{11} \mathrm{C}$-HED ${ }^{11} \mathrm{C}$-hydroxyephedrine, ${ }^{18} \mathrm{~F}$-LMI1 $195 \mathrm{~N}$-[3-Bromo-4-(3-[ $\left.{ }^{18} \mathrm{~F}\right]$ fluoro-propoxy)-benzyl]-guanidine, ${ }^{18} \mathrm{~F}-4 F-M P H G{ }^{18} \mathrm{~F}$-fluoro-3-hydroxyphenethylguanidine, ${ }^{18} \mathrm{~F}$ - $3 \mathrm{~F}$-PHPG $3-{ }^{18} \mathrm{~F}$-fluoro-4-hydroxyphenethylguanidine

terminal similar to physiological NE [35, 57]. Encouraging results from a recently published phase- 2 trial demonstrated that the kinetics of ${ }^{18} \mathrm{~F}$-LMI1195 might be superior to ${ }^{11} \mathrm{C}$ HED: this could pave the way for a phase-3 trial to evaluate the potential role of ${ }^{18} \mathrm{~F}$-LMI1195 for risk stratification among HF patients [54]. On the contrary, ${ }^{18} \mathrm{~F}-4 \mathrm{~F}-\mathrm{MPHG}$ and ${ }^{18} \mathrm{~F}-3 \mathrm{~F}-\mathrm{PHPG}$ offer the advantage of slow neuronal uptake and long neuronal retention and, therefore, such radiotracers are capable of reflecting even modest alterations of cardiac sympathetic nerve conditions by kinetic analyses [55]. Nonetheless, future studies should focus on the underlying mechanisms of these PET and SPECT agents, in particular to guide the clinical reader in interpreting imaging results or to combine multiple radiotracers with different kinetic properties to gain further insight into NE handling at the nerve terminal.

Acknowledgements This work was supported by the Competence Network of Heart Failure funded by the Integrated Research and Treatment Center (IFB) of the Federal Ministry of Education and Research (BMBF) and German Research Council (DFG Grant HI 1789/3-3). This project has received funding from the European Union's Horizon 2020 research and innovation programme under the Marie SklodowskaCurie grant agreement No 701983. 
Author's Contributions RAW: Literature search, Literature review, Writing, Editing, Content planning. XC: Literature search, Literature review. MH: Editing, Content planning, Other (Figures). SPR: Literature review, Writing, Editing. CL: Literature review, Writing, Editing. MSJ: Literature review, Writing, Editing, Content planning, Other (Project Development). TH: Literature search, Literature review, Writing, Editing, Content planning, Other (Project Development).

\section{Compliance with ethics guidelines}

Conflict of interest All authors (RAW, XC, MH, SPR, CL, MSJ, TH) declare that they do not have any conflict of interest.

Research involving human and animal participants The article contains data from studies with animal subjects performed by the authors of this article. All institutional and national guidelines for the care and use of laboratory animals were followed. All procedures performed in studies involving animals were in accordance with the ethical standards of the institution or practice at which the studies were conducted. This article does not contain any studies with human participants performed by any of the authors.

Open Access This article is distributed under the terms of the Creative Commons Attribution 4.0 International License (http://creativeco mmons.org/licenses/by/4.0/), which permits unrestricted use, distribution, and reproduction in any medium, provided you give appropriate credit to the original author(s) and the source, provide a link to the Creative Commons license, and indicate if changes were made.

\section{References}

1. Zhang DY, Anderson AS (2014) The sympathetic nervous system and heart failure. Cardiol Clin 32(1):33-45. https://doi. org/10.1016/j.ccl.2013.09.010

2. Parati G, Esler M (2012) The human sympathetic nervous system: its relevance in hypertension and heart failure. Eur Heart $\mathbf{J}$ 33(9):1058-1066. https://doi.org/10.1093/eurheartj/ehs041

3. Veith RC, Featherstone JA, Linares OA, Halter JB (1986) Age differences in plasma norepinephrine kinetics in humans. J Gerontol 41(3):319-324

4. Liang CS (2007) Cardiac sympathetic nerve terminal function in congestive heart failure. Acta Pharmacol Sin 28(7):921-927. https ://doi.org/10.1111/j.1745-7254.2007.00585.x

5. Mann DL, Kent RL, Parsons B, Gt Cooper (1992) Adrenergic effects on the biology of the adult mammalian cardiocyte. Circulation 85(2):790-804

6. Schlaich MP, Kaye DM, Lambert E, Sommerville M, Socratous F, Esler MD (2003) Relation between cardiac sympathetic activity and hypertensive left ventricular hypertrophy. Circulation 108(5):560-565. https://doi.org/10.1161/01.CIR.0000081775 72651.B6

7. The Cardiac Insufficiency Bisoprolol Study II (CIBIS-II): a randomised trial (1999) Lancet 353(9146):9-13

8. Ekman M, Zethraeus N, Jonsson B (2001) Cost effectiveness of bisoprolol in the treatment of chronic congestive heart failure in Sweden: analysis using data from the Cardiac Insufficiency Bisoprolol Study II trial. Pharmacoeconomics 19(9):901-916

9. Cohn JN, Pfeffer MA, Rouleau J, Sharpe N, Swedberg K, Straub M, Wiltse C, Wright TJ, Investigators M (2003) Adverse mortality effect of central sympathetic inhibition with sustained-release moxonidine in patients with heart failure (MOXCON). Eur J Heart Fail 5(5):659-667

10. Bengel FM (2011) Imaging targets of the sympathetic nervous system of the heart: translational considerations. J Nucl Med 52(8):1167-1170. https://doi.org/10.2967/jnumed.110.084228

11. Thackeray JT, Bengel FM (2016) PET imaging of the autonomic nervous system. Q J Nucl Med Mol Imaging 60(4):362-382

12. Chen X, Werner RA, Javadi MS, Maya Y, Decker M, Lapa C, Herrmann K, Higuchi T (2015) Radionuclide imaging of neurohormonal system of the heart. Theranostics 5(6):545-558. https ://doi.org/10.7150/thno.10900

13. Nakajima K, Nakata $T$ (2015) Cardiac 123I-MIBG imaging for clinical decision making: 22-year experience in Japan. J Nucl Med 56(Suppl 4):11S-19S. https://doi.org/10.2967/jnume d.114.142794

14. Nakajima K, Scholte A, Nakata T, Dimitriu-Leen AC, Chikamori T, Vitola JV, Yoshinaga K (2017) Cardiac sympathetic nervous system imaging with (123)I-meta-iodobenzylguanidine: perspectives from Japan and Europe. J Nucl Cardiol 24(3):952960. https://doi.org/10.1007/s12350-017-0818-y

15. Henzlova MJ, Duvall WL, Einstein AJ, Travin MI, Verberne HJ (2016) ASNC imaging guidelines for SPECT nuclear cardiology procedures: stress, protocols, and tracers. J Nucl Cardiol 23(3):606-639. https://doi.org/10.1007/s12350-015-0387-x

16. Verberne HJ, Brewster LM, Somsen GA, van Eck-Smit BL (2008) Prognostic value of myocardial 123I-metaiodobenzylguanidine (MIBG) parameters in patients with heart failure: a systematic review. Eur Heart J 29(9):1147-1159. https://doi. org/10.1093/eurheartj/ehn113

17. Jacobson AF, Senior R, Cerqueira MD, Wong ND, Thomas GS, Lopez VA, Agostini D, Weiland F, Chandna H, Narula J, Investigators A-H (2010) Myocardial iodine-123 meta-iodobenzylguanidine imaging and cardiac events in heart failure. Results of the prospective ADMIRE-HF (AdreView Myocardial Imaging for Risk Evaluation in Heart Failure) study. J Am Coll Cardiol 55(20):2212-2221. https://doi.org/10.1016/j.jacc.2010.01.014

18. Nakajima K, Nakata T, Matsuo S, Jacobson AF (2016) Creation of mortality risk charts using 123I meta-iodobenzylguanidine heart-to-mediastinum ratio in patients with heart failure: 2- and 5-year risk models. Eur Heart J Cardiovasc Imaging 17(10):1138-1145. https://doi.org/10.1093/ehjci/jev322

19. Auricchio A, Schloss EJ, Kurita T, Meijer A, Gerritse B, Zweibel S, AlSmadi FM, Leng CT, Sterns LD, PainFree SSTI (2015) Low inappropriate shock rates in patients with single- and dual/ triple-chamber implantable cardioverter-defibrillators using a novel suite of detection algorithms: PainFree SST trial primary results. Heart Rhythm 12(5):926-936. https://doi.org/10.1016/j. hrthm.2015.01.017

20. Gasparini M, Proclemer A, Klersy C, Kloppe A, Lunati M, Ferrer JB, Hersi A, Gulaj M, Wijfels MC, Santi E, Manotta L, Arenal A (2013) Effect of long-detection interval vs standarddetection interval for implantable cardioverter-defibrillators on antitachycardia pacing and shock delivery: the ADVANCE III randomized clinical trial. JAMA 309(18):1903-1911. https:// doi.org/10.1001/jama.2013.4598

21. Moss AJ, Greenberg H, Case RB, Zareba W, Hall WJ, Brown MW, Daubert JP, McNitt S, Andrews ML, Elkin AD, Multicenter Automatic Defibrillator Implantation Trial IIRG (2004) Long-term clinical course of patients after termination of ventricular tachyarrhythmia by an implanted defibrillator. Circulation 110(25):3760-3765. https://doi.org/10.1161/01.CIR.00001 50390.04704.B7

22. Verschure DO, de Groot JR, Mirzaei S, Gheysens O, Nakajima K, van Eck-Smit BLF, Aernout Somsen G, Verberne HJ (2017) Cardiac (123)I-mIBG scintigraphy is associated with freedom of appropriate ICD therapy in stable chronic heart failure 
patients. Int J Cardiol 248:403-408. https://doi.org/10.1016/j. ijcard.2017.08.003

23. Ketchum ES, Jacobson AF, Caldwell JH, Senior R, Cerqueira MD, Thomas GS, Agostini D, Narula J, Levy WC (2012) Selective improvement in Seattle Heart Failure Model risk stratification using iodine-123 meta-iodobenzylguanidine imaging. J Nucl Cardiol 19(5):1007-1016. https://doi.org/10.1007/s1235 0-012-9603-0

24. Strauss DG, Selvester RH, Wagner GS (2011) Defining left bundle branch block in the era of cardiac resynchronization therapy. Am J Cardiol 107(6):927-934. https://doi.org/10.1016/j.amjca rd.2010.11.010

25. Nishioka SA, Martinelli Filho M, Brandao SC, Giorgi MC, Vieira ML, Costa R, Mathias W, Meneghetti JC (2007) Cardiac sympathetic activity pre and post resynchronization therapy evaluated by 123I-MIBG myocardial scintigraphy. J Nucl Cardiol 14(6):852859. https://doi.org/10.1016/j.nuclcard.2007.08.004

26. Travin MI (2017) Current clinical applications and next steps for cardiac innervation imaging. Curr Cardiol Rep 19(1):1. https:// doi.org/10.1007/s11886-017-0817-2

27. Brignole $\mathrm{M}$, Auricchio A, Baron-Esquivias G, Bordachar P, Boriani G, Breithardt OA, Cleland J, Deharo JC, Delgado V, Elliott PM, Gorenek B, Israel CW, Leclercq C, Linde C, Mont L, Padeletti L, Sutton R, Vardas PE, Zamorano JL, Achenbach S, Baumgartner H, Bax JJ, Bueno H, Dean V, Deaton C, Erol C, Fagard R, Ferrari R, Hasdai D, Hoes AW, Kirchhof P, Knuuti J, Kolh P, Lancellotti P, Linhart A, Nihoyannopoulos P, Piepoli MF, Ponikowski P, Sirnes PA, Tamargo JL, Tendera M, Torbicki A, Wijns W, Windecker S, Document R, Kirchhof P, Blomstrom-Lundqvist C, Badano LP, Aliyev F, Bansch D, Baumgartner H, Bsata W, Buser P, Charron P, Daubert JC, Dobreanu D, Faerestrand S, Hasdai D, Hoes AW, Le Heuzey JY, Mavrakis H, McDonagh T, Merino JL, Nawar MM, Nielsen JC, Pieske B, Poposka L, Ruschitzka F, Tendera M, Van Gelder IC, Wilson CM, Guidelines ESCCFP (2013) 2013 ESC Guidelines on cardiac pacing and cardiac resynchronization therapy: the Task Force on cardiac pacing and resynchronization therapy of the European Society of Cardiology (ESC). Developed in collaboration with the European Heart Rhythm Association (EHRA). Eur Heart J 34(29):2281-2329. https://doi.org/10.1093/eurheartj/eht150

28. De Marco T, Dae M, Yuen-Green MS, Kumar S, Sudhir K, Keith F, Amidon TM, Rifkin C, Klinski C, Lau D et al (1995) Iodine-123 metaiodobenzylguanidine scintigraphic assessment of the transplanted human heart: evidence for late reinnervation. J Am Coll Cardiol 25(4):927-931

29. Gerson MC, Caldwell JH, Ananthasubramaniam K, Clements IP, Henzlova MJ, Amanullah A, Jacobson AF (2011) Influence of diabetes mellitus on prognostic utility of imaging of myocardial sympathetic innervation in heart failure patients. Circ Cardiovasc Imaging 4(2):87-93. https://doi.org/10.1161/CIRCIMAGIN G.110.954784

30. Sobajima M, Ueno H, Onoda H, Kuwahara H, Tanaka S, Ushijima R, Fukuda N, Yokoyama S, Nagura S, Doi T, Yamashita A, Fukahara K, Ito H, Kinugawa K (2018) Transcatheter aortic valve implantation improves cardiac sympathetic nerve activity on (123) I-metaiodobenzylguanidine myocardial scintigraphy in severe aortic valve stenosis. Circ J 82(2):579-585. https://doi.org/10.1253/ circj.cj-17-0817

31. Yamamoto S, Suzuki H, Sugimura K, Tatebe S, Aoki T, Miura M, Yaoita N, Sato H, Kozu K, Ota H, Takanami K, Takase K, Shimokawa H (2016) Focal reduction in cardiac (123)I-metaiodobenzylguanidine uptake in patients with anderson-fabry disease. Circ J 80(12):2550-2551. https://doi.org/10.1253/circj .CJ-16-0690
32. Imbriaco M, Pellegrino T, Piscopo V, Petretta M, Ponsiglione A, Nappi C, Puglia M, Dell'Aversana S, Riccio E, Spinelli L, Pisani A, Cuocolo A (2017) Cardiac sympathetic neuronal damage precedes myocardial fibrosis in patients with Anderson-Fabry disease. Eur J Nucl Med Mol Imaging 44(13):2266-2273. https:// doi.org/10.1007/s00259-017-3778-1

33. Yoshita M, Taki J, Yokoyama K, Noguchi-Shinohara M, Matsumoto Y, Nakajima K, Yamada M (2006) Value of 123I-MIBG radioactivity in the differential diagnosis of DLB from AD. Neurology 66(12):1850-1854. https://doi.org/10.1212/01.wnl.00002 19640.59984.a7

34. Simoes MV, Barthel P, Matsunari I, Nekolla SG, Schomig A, Schwaiger M, Schmidt G, Bengel FM (2004) Presence of sympathetically denervated but viable myocardium and its electrophysiologic correlates after early revascularised, acute myocardial infarction. Eur Heart J 25(7):551-557. https://doi.org/10.1016/j. ehj.2004.02.016

35. Werner RA, Rischpler C, Onthank D, Lapa C, Robinson S, Samnick S, Javadi M, Schwaiger M, Nekolla SG, Higuchi T (2015) Retention kinetics of the 18F-labeled sympathetic nerve PET tracer LMI1195: comparison with 11C-hydroxyephedrine and 123I-MIBG. J Nucl Med 56(9):1429-1433. https://doi. org/10.2967/jnumed.115.158493

36. Munch G, Nguyen NT, Nekolla S, Ziegler S, Muzik O, Chakraborty P, Wieland DM, Schwaiger M (2000) Evaluation of sympathetic nerve terminals with [(11)C]epinephrine and [(11)C] hydroxyephedrine and positron emission tomography. Circulation 101(5):516-523

37. Bravo PE, Lautamaki R, Carter D, Holt DP, Nekolla SG, Dannals RF, Russell SD, Bengel FM (2015) Mechanistic insights into sympathetic neuronal regeneration: multitracer molecular imaging of catecholamine handling after cardiac transplantation. Circ Cardiovasc Imaging 8(8):e003507. https://doi.org/10.1161/CIRCI MAGING.115.003507

38. Fujita W, Matsunari I, Aoki H, Nekolla SG, Kajinami K (2016) Prediction of all-cause death using C-11-hydroxyephedrine positron emission tomography in Japanese patients with left ventricular dysfunction. Ann Nucl Med 30(7):461-467. https://doi. org/10.1007/s12149-016-1081-z

39. Fallavollita JA, Heavey BM, Luisi AJ Jr, Michalek SM, Baldwa S, Mashtare TL Jr, Hutson AD, Dekemp RA, Haka MS, Sajjad M, Cimato TR, Curtis AB, Cain ME, Canty JM Jr (2014) Regional myocardial sympathetic denervation predicts the risk of sudden cardiac arrest in ischemic cardiomyopathy. J Am Coll Cardiol 63(2):141-149. https://doi.org/10.1016/j.jacc.2013.07.096

40. Kasai T, Bradley TD (2011) Obstructive sleep apnea and heart failure pathophysiologic and therapeutic implications. J Am Coll Cardiol 57(2):119-127. https://doi.org/10.1016/j.jacc.2010.08.627

41. Hall AB, Ziadi MC, Leech JA, Chen SY, Burwash IG, Renaud J, deKemp RA, Haddad H, Mielniczuk LM, Yoshinaga K, Guo A, Chen L, Walter O, Garrard L, DaSilva JN, Floras JS, Beanlands RSB (2014) Effects of short-term continuous positive airway pressure on myocardial sympathetic nerve function and energetics in patients with heart failure and obstructive sleep apnea a randomized study. Circulation 130(11):892-901. https://doi. org/10.1161/Circulationaha.113.005893

42. Ducharme J, Goertzen AL, Patterson J, Demeter S (2009) Practical aspects of 18F-FDG PET when receiving 18F-FDG from a distant supplier. J Nucl Med Technol 37(3):164-169. https://doi. org/10.2967/jnmt.109.062950

43. Raffel DM, Jung YW, Gildersleeve DL, Sherman PS, Moskwa JJ, Tluczek LJ, Chen W (2007) Radiolabeled phenethylguanidines: novel imaging agents for cardiac sympathetic neurons and adrenergic tumors. J Med Chem 50(9):2078-2088. https://doi. org/10.1021/jm061398y 
44. Kobayashi R, Chen X, Werner RA, Lapa C, Javadi MS, Higuchi T (2017) New horizons in cardiac innervation imaging: introduction of novel (18)F-labeled PET tracers. Eur J Nucl Med Mol Imaging 44(13):2302-2309. https://doi.org/10.1007/s00259-017-3828-8

45. Yu M, Bozek J, Lamoy M, Guaraldi M, Silva P, Kagan M, Yalamanchili P, Onthank D, Mistry M, Lazewatsky J, Broekema M, Radeke H, Purohit A, Cdebaca M, Azure M, Cesati R, Casebier D, Robinson SP (2011) Evaluation of LMI1195, a novel 18F-labeled cardiac neuronal PET imaging agent, in cells and animal models. Circ Cardiovasc Imaging 4(4):435-443. https://doi.org/10.1161/ CIRCIMAGING.110.962126

46. Higuchi T, Yousefi BH, Reder S, Beschorner M, Laitinen I, Yu M, Robinson S, Wester HJ, Schwaiger M, Nekolla SG (2015) Myocardial kinetics of a novel [(18)F]-labeled sympathetic nerve PET tracer LMI1195 in the isolated perfused rabbit heart. JACC Cardiovasc Imaging 8(10):1229-1231. https://doi.org/10.1016/j. jemg.2014.11.013

47. Yu M, Bozek J, Lamoy M, Kagan M, Benites P, Onthank D, Robinson SP (2012) LMI1195 PET imaging in evaluation of regional cardiac sympathetic denervation and its potential role in antiarrhythmic drug treatment. Eur J Nucl Med Mol Imaging 39(12):1910-1919. https://doi.org/10.1007/s00259-012-2204-y

48. Dae MW, De Marco T, Botvinick EH, O'Connell JW, Hattner RS, Huberty JP, Yuen-Green MS (1992) Scintigraphic assessment of MIBG uptake in globally denervated human and canine heartsimplications for clinical studies. J Nucl Med 33(8):1444-1450

49. Werner RA, Kobayashi R, Javadi MS, Koeck Z, Wakabayashi H, Unterecker S, Nakajima K, Lapa C, Menke A, Higuchi T (2018) Impact of novel antidepressants on cardiac metaiodobenzylguanidine (mIBG) uptake: experimental studies in SK-N-SH cells and healthy rabbits. J Nucl Med. https://doi.org/10.2967/jnume d.117.206045

50. Chen X, Werner RA, Lapa C, Nose N, Hirano M, Javadi MS, Robinson S, Higuchi T (2018) Subcellular storage and release mode of the novel (18)F-labeled sympathetic nerve PET tracer LMI1195. EJNMMI Res 8(1):12. https://doi.org/10.1186/s1355 0-018-0365-9

51. Higuchi T, Yousefi BH, Kaiser F, Gartner F, Rischpler C, Reder S, Yu M, Robinson S, Schwaiger M, Nekolla SG (2013) Assessment of the 18F-labeled PET tracer LMI1195 for imaging norepinephrine handling in rat hearts. J Nucl Med 54(7):1142-1146. https:// doi.org/10.2967/jnumed.112.104232
52. Rischpler C, Fukushima K, Isoda T, Javadi MS, Dannals RF, Abraham R, Wahl R, Bengel FM, Higuchi T (2013) Discrepant uptake of the radiolabeled norepinephrine analogues hydroxyephedrine (HED) and metaiodobenzylguanidine (MIBG) in rat hearts. Eur J Nucl Med Mol Imaging 40(7):1077-1083. https:// doi.org/10.1007/s00259-013-2393-z

53. Sinusas AJ, Lazewatsky J, Brunetti J, Heller G, Srivastava A, Liu YH, Sparks R, Puretskiy A, Lin SF, Crane P, Carson RE, Lee LV (2014) Biodistribution and radiation dosimetry of LMI1195: first-in-human study of a novel 18F-labeled tracer for imaging myocardial innervation. J Nucl Med 55(9):1445-1451. https:// doi.org/10.2967/jnumed.114.140137

54. Zelt J, Ranaud J, Mielniczuk L, Garrard L, Walter O, Guo A, deKemp R, Beanlands R (2018) 1312 M-07-Fluorine-18 LMI1195 positron emission tomography provides accurate measure of cardiac sympathetic innervation compared to carbon-11 hydroxyephedrine. In: Abstract of the 67th Annual Scientifc Session \& Expo, American College of Cardiology

55. Jung YW, Jang KS, Gu G, Koeppe RA, Sherman PS, Quesada CA, Raffel DM (2017) [(18)F]Fluoro-Hydroxyphenethylguanidines: efficient Synthesis and comparison of two structural isomers as radiotracers of cardiac sympathetic innervation. ACS Chem Neurosci 8(7):1530-1542. https://doi.org/10.1021/acschemneu ro. $7 \mathrm{~b} 00051$

56. Jang KS, Jung YW, Gu G, Koeppe RA, Sherman PS, Quesada CA, Raffel DM (2013) 4-[18F]Fluoro-m-hydroxyphenethylguanidine: a radiopharmaceutical for quantifying regional cardiac sympathetic nerve density with positron emission tomography. J Med Chem 56(18):7312-7323. https://doi.org/10.1021/jm400770g

57. Raffel D, Jung YW, Murthy V, Gu G, Rothley J, Koeppe R, Frey K (2016) First-in-human studies of 18F-hydroxyphenethylguanidines: pET radiotracers for quantifying cardiac sympathetic nerve density. J Nucl Med 57(supplement 2):232

58. Tinti E, Positano V, Giorgetti A, Marzullo P (2014) Feasibility of [(123)I]-meta-iodobenzylguanidine dynamic 3-D kinetic analysis in vivo using a CZT ultrafast camera: preliminary results. Eur $\mathbf{J}$ Nucl Med Mol Imaging 41(1):167-173. https://doi.org/10.1007/ s00259-013-2549-x

59. Werner RA, Chen X, Hirano M, Nose N, Lapa C, Javadi MS, Higuchi T (2018) The impact of ageing on [11C]meta-hydroxyephedrine uptake in the rat heart. J Nucl Med 59(supplement 1): 100 